\title{
Effect of Inoculum Concentration and Calcium Salts on Infection of Apple Fruit by Botryosphaeria dothidea
}

\author{
Alan R. Biggs, West Virginia University, Kearneysville Tree Fruit Research and Education Center, P.O. Box 609, \\ Kearneysville 25430
}

\begin{abstract}
Biggs, A. R. 2004. Effect of inoculum concentration and calcium salts on infection of apple fruit by Botryosphaeria dothidea. Plant Dis. 88:147-151.
\end{abstract}

The objective of this study was to determine the effects of calcium salts on growth of Botryosphaeria dothidea and incidence of white rot. The relative virulence of five $B$. dothidea isolates was determined using the apple cultivars Fuji, Gala, Golden Delicious, Liberty, and York. Cultivar and isolate differences in lesion diameter were significant. Cultivar differences occurred between Fuji, which was most susceptible, and Gala, which was least susceptible. Isolates PA-1 and PA-2 were most virulent. Isolate PA- 4 was used at conidia concentrations of 1 $\times 10^{4}, 1 \times 10^{5}, 1 \times 10^{6}$, and $1 \times 10^{7}$ conidia per ml on Golden Delicious fruit to test the effects of four inoculum concentrations on fruit infection by $B$. dothidea. Incidence of infection on detached, nonwounded fruit increased as inoculum concentration increased. The effects of four calcium salts on infection of wounded fruit by conidia were examined in field and laboratory experiments. In the field experiments, lesion size was slightly reduced on fruit treated with either calcium hydroxide or calcium silicate after wounding and prior to inoculation with conidia of $B$ dothidea, whereas lesions that developed at wounds treated with calcium chloride or calcium propionate were similar to those of the control. In the laboratory experiments, in several instances supplementation with calcium salts resulted in increased lesion diameter relative to the control. Two of five isolates tested showed increased percent germination with all four calcium salts, and one isolate showed increased germination in the presence of two of the four calcium salts. Germ tube elongation was not affected by calcium salts for four out of five isolates tested. There was significant variation among isolates and calcium salts on the growth of $B$. dothidea in liquid culture. Calcium chloride and calcium hydroxide enhanced the growth of three isolates and had no effect on the other three isolates. Calcium propionate inhibited the growth of four isolates and had no effect on the other two isolates. Calcium silicate inhibited the growth of one isolate and had no effect on the other five isolates.

Additional keywords: black rot, bot rot, Botryosphaeria obtusa

White rot, caused by Botryosphaeria dothidea, is a destructive fruit rot and canker pathogen of apple and pear in the southern, central, and mid-Atlantic regions of the United States (24). Fruit rot caused by $B$. dothidea was first reported in the United States by E. A. Fenner in 1925 (18), whereas the canker phase of white rot was first reported in South Africa in 1919 (21). The canker phase was considered relatively unimportant in the United States prior to 1952 , when the pathogen was isolated from apple tree cankers in Indiana (22). The disease also has been reported in Australia, Argentina, and Brazil (24).

Prior to the development of effective fungicides, white rot of apples could be

Corresponding author: A. R. Biggs

E-mail: abiggs2@wvu.edu

This is Scientific Article No. 2854 of the West Virginia Agricultural and Forestry Experiment Station.

Accepted for publication 2 September 2003.

Publication no. D-2003-1124-05R

(C) 2004 The American Phytopathological Society extensive, with up to $50 \%$ crop loss following periods of favorable weather. With the advent of modern fungicides, the disease is less prevalent than in the past, largely due to the efficacy of captan and the benzimidazole fungicides, benomyl and thiophanate-methyl. The ethylene-bis dithiocarbamates (EBDCs) are only marginally effective against the white rot pathogen. With the more limiting re-entry intervals for captan, the loss of benomyl registration, the expense of thiophanatemethyl, and marginal prices for apples, significant fruit losses from white rot have occurred in years when weather conditions have been favorable and less effective fungicides were used. Although disease control is achieved primarily with the use of fungicides (20), orchard sanitation is an integral part of disease management (24).

Application of supplemental calcium to apples is a routine practice in orchards that are prone to calcium-related nutritional disorders such as cork spot and bitter pit. The most common form of calcium supplement is calcium chloride (as a 75\% food-grade flake); however, many proprietary products containing calcium in other forms, or combined with other nutrients, are available. Calcium supplements are most often applied beginning 2 to 4 weeks after petal fall and may continue through the preharvest period for as many as nine applications. Recommended usage rates of calcium chloride range from 17 to $56 \mathrm{~kg} / \mathrm{ha} /$ year based on the potential severity of the nutritional disorders (20).

In addition to controlling nutritional disorders, increasing the calcium content of fruits and vegetables prolongs their storage life. This effect is thought to be due mainly to $\mathrm{Ca}$ ions becoming associated with pectic substances and reducing the efficacy of pathogen polygalacturonases $(1,16)$. Much of the research with apples on enhancing storage quality and reducing decay with calcium supplementation has been done in the postharvest environment (11-15). Relatively few studies have examined the potential role of calcium supplementation in the preharvest period for reducing disease. In field trials where fruit received three weekly dilute applications of calcium solutions, fruit treated with calcium salts and then inoculated with conidia of either $C$. gloeosporioides or $C$. acutatum exhibited lower incidence of infection when compared to control fruit (3). Alternaria rot of the apple cultivar Nittany was effectively managed with preand postharvest calcium applications (7). These experiments demonstrated that calcium salts have suppressive activity against fungal pathogens in the field and possibly could be used as part of an integrated disease management program, such as that proposed by Sugar (23) for pears. However, application of a higherthan-normal amount of a nutritional supplement, in this case calcium chloride, to a disease management program in which several diseases are already managed effectively could disrupt the balance of that system, perhaps leading inadvertently to an increase in one of the other diseases. Before increased amounts of calcium chloride are widely recommended, some additional knowledge of their impact on other organisms is warranted. The objective of this study was to determine the effects of $\mathrm{Ca}$ salts on growth of $B$. dothidea and incidence of white rot.

\section{MATERIALS AND METHODS \\ Effects of fungal isolates on infection of wounded apple fruit by $B$. dothidea.}


Five isolates of $B$. dothidea and two isolates of B. obtusa, the cause of black rot, were obtained from apple in 1998 and 1999 from diseased fruit collected in Pennsylvania, Maryland, West Virginia, and Virginia. The isolates were cultured on potato dextrose agar (PDA) and maintained at $4^{\circ} \mathrm{C}$. The relative virulence of the isolates was determined using the apple cultivars Fuji, Gala, Golden Delicious, Liberty, and York. Fruit were collected approximately 3 weeks prior to their normal harvest date, arranged in trays, wounded to a depth of approximately 1 $\mathrm{mm}$ with an 8-mm-diameter cork borer (the circumscribed epidermis removed to expose the underlying tissue), and inoculated with an 8-mm-diameter plug of agar and mycelium. Inoculated and control fruit (treated with agar only) were wrapped with a 2.5-cm-diameter-wide strip of Parafilm to maintain moisture over the inoculation site and placed in plastic trays with lids and kept at $22 \pm 2^{\circ} \mathrm{C}$ for 5 days, after which lesion diameter was measured. Lesions were assessed by measuring the length and width of lesions and calculating the mean diameter. The experiment used three replicates of eight fruit each and eight control fruit and was conducted twice for each cultivar (one experiment initiated on each of two consecutive days) in August, September, and October 2001. Data were subjected to analysis of variance and means separated with the WallerDuncan $k$-ratio $t$ test (SAS Institute, Cary, NC.).

Effects of four inoculum concentrations on nonwounded fruit infection by $B$. dothidea. Isolate PA-4 was used at conidia concentrations of $1 \times 10^{4}, 1 \times 10^{5}$, $1 \times 10^{6}$, and $1 \times 10^{7}$ conidia per $\mathrm{ml}$ on Golden Delicious fruit. Detached fruit were inoculated by using microcentrifuge tubes attached to the fruit surface with modeling clay as described previously (3). Percent incidence of decay was determined $10,12,14,17$, and 19 days after inoculation. The experiment was a completely randomized design with three replications of eight fruit for each inoculum concentration and a control that was inoculated with sterile distilled water. The experiment was conducted twice in September 2001. Data were subjected to analysis of variance and means separated with the Waller-Duncan $k$-ratio $t$ test (SAS Institute).

Effects of four calcium salts on infection of wounded fruit by conidia of B. dothidea. Field experiments. Golden Delicious fruit on the tree were wounded with a 5-mm-diameter cork borer, and the epidermis within the wound was removed with a scalpel. Wounds were sprayed with a hand-held spray bottle with calcium salt solutions containing $1,000 \mathrm{mg}$ of $\mathrm{Ca}^{++}$per liter (calcium chloride, calcium propionate, calcium silicate, or calcium hydroxide) and allowed to dry. A 5-mm-diameter filter paper disk was dipped in a suspension of B. dothidea isolate PA-4 at $1 \times 10^{6}$ conidia per $\mathrm{ml}$ and placed over the calcium-treated wound, which was then wrapped with Parafilm. The Parafilm was removed and mean lesion diameter was determined 10 days after inoculation. The experiment was a completely randomized design with three replications of eight fruit for each salt and a control that was inoculated with a filter paper disk without inoculum. The experiment was conducted twice in September 2001. Data were subjected to analysis of variance and means separated with the Waller-Duncan $k$-ratio $t$ test (SAS Institute).

Laboratory experiments. Harvested Golden Delicious fruit were wounded, treated with calcium salts, inoculated as described above, and then placed on paper trays within plastic boxes with lids. The experiment was conducted four times, twice with isolate PA-1 and twice with isolate PA-4. The Parafilm was removed and mean lesion diameter was determined 5 and 7 days after inoculation. The experiment was a completely randomized design with three replications of eight fruit for each salt and a control that was inoculated with a filter paper disk without inoculum. The experiment was conducted twice in September 2001. Data were subjected to analysis of variance and means separated with the Waller-Duncan $k$-ratio $t$ test (SAS Institute).
Effects of four calcium salts on $B$. dothidea conidia germination and germ tube elongation. Conidia from five $B$. dothidea isolates were placed on water agar containing calcium salts at $1,000 \mathrm{mg}$ of $\mathrm{Ca}^{++}$per liter (calcium chloride, calcium propionate, calcium silicate, or calcium hydroxide). Percent germination was determined $3 \mathrm{~h}$ after placing conidia on the calcium-supplemented water agar by making three replicate counts of 50 conidia at $\times 100$ magnification. Germ tube elongation was determined after $5 \mathrm{~h}$ and was made from three replicates of 10 conidia with germ tubes. The experiment was conducted twice and was a completely randomized design with three replications of 50 conidia for each salt and a water agar control, or three replications of 10 conidia with germ tubes for each salt and a water agar control. Data were subjected to analysis of variance and means separated with the WallerDuncan $k$-ratio $t$ test (SAS Institute).

Effects of four calcium salts on growth in liquid media of five $B$. dothidea isolates. To assess the effects of calcium salts on mycelial growth, salts were prepared in sterile, deionized distilled water and were added to autoclaved, warm $\left(45\right.$ to $\left.55^{\circ} \mathrm{C}\right) 2 \%$ potato dextrose broth (PDB) to provide a range of concentrations including $0,300,600,900,1,200$ and $2,400 \mathrm{mg}$ of calcium per liter, and the media were poured into $250-\mathrm{ml}$ stationary flasks. Calcium concentrations were chosen based on amounts of calcium that could be present in the apoplast or symplast during the host-pathogen interaction, on fruit surfaces following calcium application in the field, or in postharvest systems in which calcium is used to enhance the activity of biological control organisms. A 30- $\mu \mathrm{l}$ drop of a suspension of $1 \times 10^{5}$ conidia from each isolate was placed in each flask. Flasks were incubated in the dark at $20 \pm 2^{\circ} \mathrm{C}$, and growth was assessed after 14 days by determining the dry weight of the mycelium. The experiment was performed three times with three replicate flasks per treatment, and results were subjected to simple linear regression analysis (SAS Institute).

Table 1. Lesion diameter ( $\mathrm{mm} \pm$ standard error) caused by several Botryosphaeria dothidea and B. obtusa isolates on wounded apple fruit of various cultivars

\begin{tabular}{|c|c|c|c|c|c|c|}
\hline \multirow[b]{2}{*}{ Isolate } & \multicolumn{6}{|c|}{ Apple cultivar } \\
\hline & Fuji & Gala & Golden Delicious & Liberty & York & Isolate means \\
\hline B. dothidea PA-1 & $35.3 \pm 10.9^{x}$ & $22.3 \pm 2.7$ & $21.7 \pm 1.4$ & $23.0 \pm 5.3$ & $30.8 \pm 10.1$ & $26.6 \mathrm{a}^{\mathrm{y}}$ \\
\hline B. dothidea PA-2 & $35.4 \pm 10.2$ & $22.3 \pm 1.8$ & $22.7 \pm 4.0$ & $20.7 \pm 6.8$ & $30.4 \pm 4.4$ & $26.3 \mathrm{ab}$ \\
\hline B. dothidea PA-3 & $16.4 \pm 3.8$ & $16.0 \pm 4.5$ & $17.1 \pm 5.2$ & $26.5 \pm 13.3$ & $18.8 \pm 6.1$ & $19.0 \mathrm{~cd}$ \\
\hline B. dothidea PA-4 & $17.6 \pm 4.2$ & $19.8 \pm 3.6$ & $12.6 \pm 0.4$ & $15.2 \pm 2.3$ & $23.0 \pm 15.1$ & $17.3 \mathrm{~d}$ \\
\hline B. dothidea MD-1 & $19.2 \pm 5.5$ & $21.4 \pm 7.5$ & $23.1 \pm 4.9$ & $19.8 \pm 3.6$ & $14.5 \pm 3.2$ & $20.5 \mathrm{~cd}$ \\
\hline B. obtusa VA-1 & $26.6 \pm 5.6$ & $13.0 \pm 0.7$ & $22.3 \pm 4.4$ & $25.8 \pm 10.2$ & $21.5 \pm 4.0$ & $19.6 \mathrm{~cd}$ \\
\hline B. obtusa VA-2 & $20.0 \pm 3.2$ & $17.8 \pm 4.2$ & $20.6 \pm 3.4$ & $23.3 \pm 8.6$ & $20.7 \pm 3.3$ & $21.8 \mathrm{bc}$ \\
\hline Cultivar means & $24.3 \mathrm{a}^{\mathrm{z}}$ & $18.9 \mathrm{~b}$ & $20.0 \mathrm{ab}$ & $22.1 \mathrm{ab}$ & $22.8 \mathrm{ab}$ & \\
\hline
\end{tabular}

${ }^{\mathrm{x}}$ Each value for isolate and cultivar is the mean of 48 fruit from three replications of eight fruit per replication with data from two experiments combined. Data presented as means \pm standard error.

${ }^{y}$ Letters within column denote significant differences among isolate means according to the Waller-Duncan test $(P=0.05)$.

${ }^{\mathrm{z}}$ Letters within row denote significant differences among cultivar means according to the Waller-Duncan test $(P=0.05)$. 


\section{RESULTS}

Effects of fungal isolates on infection of wounded apple fruit by $B$. dothidea. Cultivar and isolate differences in lesion diameter were significant (Table 1). None of the interaction terms was significant, and the results from the two experiments were combined. Cultivar differences occurred between Fuji (most susceptible, mean lesion diameter after 5 days $=24.3$ $\mathrm{mm}$ ) and Gala (least susceptible, mean lesion diameter after 5 days $=18.9 \mathrm{~mm}$ ), with the remaining cultivars showing no significant differences in lesion diameter. B. dothidea isolates PA-1 and PA-2 were most virulent, although PA-2 did not differ in virulence from $B$. obtusa isolate VA-2. $B$. dothidea PA-4 was the least virulent isolate, although it did not vary significantly in virulence from $B$. dothidea isolates PA-3 and MD-1 and B. obtusa isolate VA-1.

Effects of four inoculum concentrations on nonwounded fruit infection by $\boldsymbol{B}$. dothidea. Infection incidence on detached, nonwounded fruit increased as inoculum concentration increased (Fig. 1). At the lowest inoculum concentration, $1 \times$ $10^{4}$ conidia per $\mathrm{ml}$, infection incidence was 6.2 and $14.6 \%$ after 10 and 19 days, respectively. At the highest inoculum concentration, $1 \times 10^{7}$ conidia per $\mathrm{ml}$, infection incidence was 79.2 and $81.9 \%$ after 10 and 19 days, respectively.

Effects of four calcium salts on infection of wounded fruit by conidia of B. dothidea. Field experiments. Results from two field experiments were similar and showed $100 \%$ incidence of infection at all inoculated sites and slightly reduced lesion size on fruit treated with either calcium hydroxide or calcium silicate after wounding and prior to inoculation with conidia of $B$. dothidea (Table 2). Lesions that developed at wounds treated with calcium chloride or calcium propionate were similar in size to the control.

Laboratory experiments. In three of four experiments conducted in the laboratory, calcium salts resulted in increased lesion diameter relative to the control (Table 2). In the two experiments with isolate PA-1, fruit treated with calcium chloride and calcium propionate exhibited larger lesions than the control. In experiment 2 with isolate PA-4, fruit treated with calcium hydroxide and calcium propionate exhibited larger lesions than the control. In experiment 1 with isolate PA-4, fruit treated with any of the four calcium salts showed reduced lesion size relative to the control.

Effects of four calcium salts on $B$. dothidea conidia germination and germ tube elongation. Two of five isolates tested (PA-1, PA-2) showed increased percent germination for all four calcium salts, and one isolate showed increased germination in the presence of two of the four calcium salts (PA-3, calcium hydroxide and calcium silicate) (Table 3 ). For two isolates, PA-4 and WV-1, percent germination was unaffected by calcium salts. Germ tube elongation was not affected by calcium salts for four out of five isolates tested. In the one isolate that exhibited differences, PA-2, calcium chloride stimulated elongation relative to the control, whereas the other calcium treatments were similar to the control.

Effects of four calcium salts on growth in liquid media of five $B$. dothidea isolates. There was significant variation among isolates and calcium salts on the growth of $B$. dothidea in liquid culture (Table 4). Calcium chloride enhanced the growth of isolates MD-1,
PA-2, and PA-4 and had no effect on the other three isolates. Calcium hydroxide enhanced the growth of isolates PA-3, PA4 , and WV-1 and had no effect on the other three isolates. Calcium propionate inhibited the growth of isolates PA-1, PA-2, PA3 , and WV-1 and had no effect on the other two isolates. Calcium silicate inhibited the growth of isolate PA2 and had no effect on the other five isolates (Table 4).

\section{DISCUSSION}

B. dothidea did not exhibit cultivar specificity when inoculated on wounded apple fruit of four different cultivars. Previous studies have shown that $B$. dothidea isolates vary in virulence on

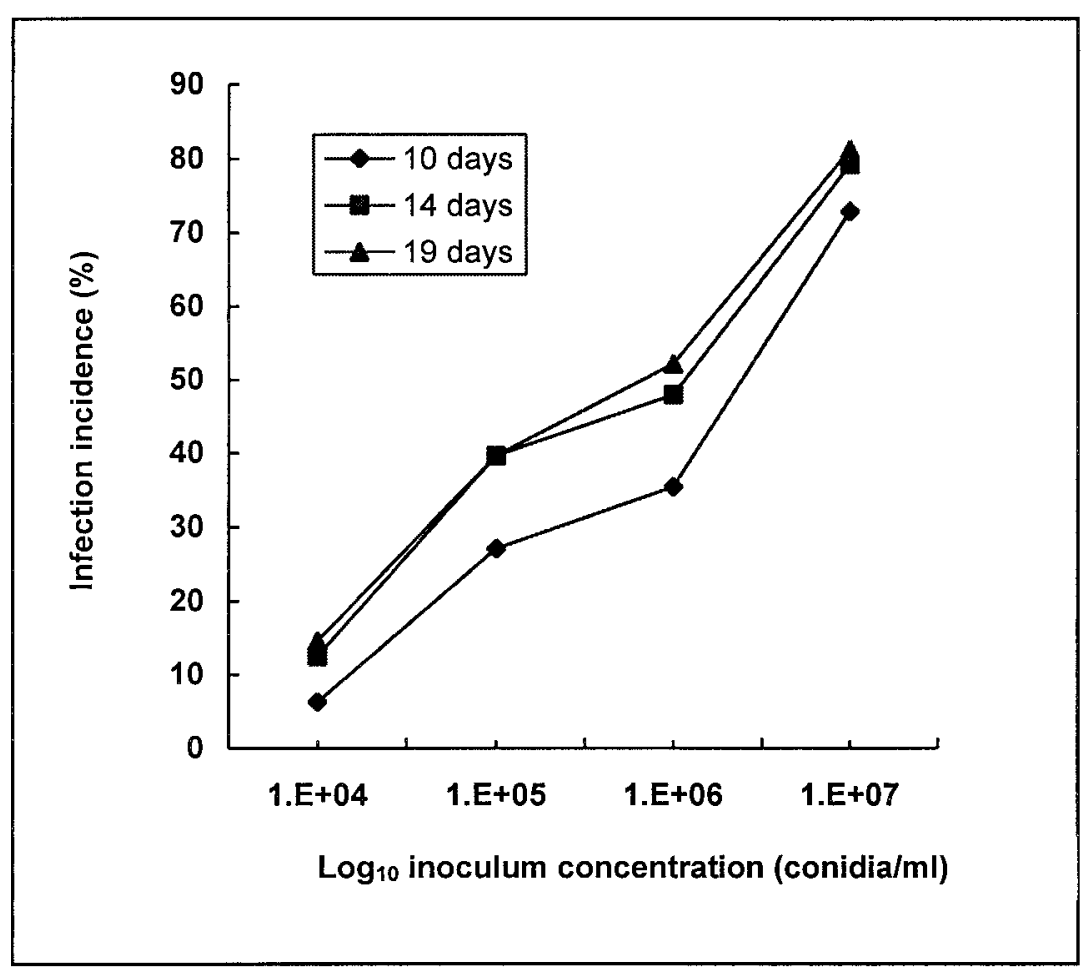

Fig. 1. Effects of four inoculum concentrations on incidence of infection on nonwounded Golden Delicious fruit inoculated with conidia of Botryosphaeria dothidea and observed at 10, 14, and 19 days postinoculation.

Table 2. Lesion diameter from wounded apple fruit treated with calcium and inoculated with conidia of Botryosphaeria dothidea

\begin{tabular}{lcccc}
\hline & \multicolumn{4}{c}{ Mean lesion diameter $(\mathbf{m m})$} \\
\cline { 2 - 5 } Treatment & $\begin{array}{c}\text { Field } \\
\text { (isolate PA-4) }^{\mathbf{w}}\end{array}$ & $\begin{array}{c}\text { Laboratory } \\
\text { (isolate PA-1) }^{\mathbf{x}}\end{array}$ & $\begin{array}{c}\text { Laboratory } \\
\text { (isolate PA-4, } \\
\text { (xperiment 1) }\end{array}$ & $\begin{array}{c}\text { Laboratory } \\
\text { (isolate PA-4, } \\
\text { experiment 2) }\end{array}$ \\
\hline Control (no calcium) & $15.3 \mathrm{a}^{\mathrm{z}}$ & $31.2 \mathrm{c}$ & $16.8 \mathrm{a}$ & $26.6 \mathrm{~b}$ \\
Calcium chloride & $13.5 \mathrm{ab}$ & $39.2 \mathrm{a}$ & $5.6 \mathrm{c}$ & $30.7 \mathrm{ab}$ \\
Calcium hydroxide & $12.8 \mathrm{~b}$ & $30.7 \mathrm{c}$ & $12.2 \mathrm{~b}$ & $33.5 \mathrm{a}$ \\
Calcium propionate & $14.4 \mathrm{ab}$ & $34.2 \mathrm{~b}$ & $7.1 \mathrm{c}$ & $32.8 \mathrm{a}$ \\
Calcium silicate & $12.6 \mathrm{~b}$ & $31.8 \mathrm{bc}$ & $6.5 \mathrm{c}$ & $25.6 \mathrm{~b}$ \\
\hline
\end{tabular}

${ }^{w}$ Mean lesion diameter 10 days after inoculation. Each value is the mean of 48 observations from fruit inoculated in the orchard (data combined from two experiments).

$\mathrm{x}$ Mean lesion diameter 7 days after inoculation. Each value is the mean of 48 observations from fruit inoculated in the laboratory (data combined from two experiments).

${ }^{y}$ Mean lesion diameter 7 days after inoculation. Each value is the mean of 24 observations from fruit inoculated in the laboratory.

${ }^{\mathrm{z}}$ Letters within columns denote significant differences among means according to the Waller-Duncan test $(P=0.05)$. 
apple fruit and stem tissues $(9,19)$, and our results support these observations. Infection incidence on intact fruit increased as inoculum concentration increased. After 19 days, infection incidence was 14.6 and $81.9 \%$ following inoculation with $1 \times 10^{4}$ and $1 \times 10^{7}$ conidia per $\mathrm{ml}$, respectively. Infection of fruit in middle and late season occurs primarily through cracks in the cuticle or wounds, although infection also could occur through lenticels (24).

Effects of calcium salts on fruit infection by $B$. dothidea in the field and laboratory were variable. Generally, but not consistently in all experiments, fruit treated with calcium chloride or calcium propionate showed similar or larger lesions relative to the control, whereas fruit treated with calcium hydroxide and calcium silicate showed similar or smaller lesions relative to the control. This is the first report of calcium application associated with increased disease severity on apples.

Some of the variability in our experiments might be explained by the presence of isolate variation in sensitivity to calcium, as was shown by Chardonnet et al. for Botrytis cinerea isolates from apple and grape (10). In their study, the biological and statistical variability that was observed among isolates of B. cinerea in response to exposure to increasing concentrations of calcium chloride was strongly affected by the fungal isolate

Table 3. Percent germination and germ tube elongation of Botryosphaeria dothidea conidia on water agar supplemented with four calcium salts

\begin{tabular}{lccccc}
\hline & \multicolumn{5}{c}{ B. dothidea isolate } \\
\cline { 2 - 6 } Treatment & PA-1 & PA-2 & PA-3 & PA-4 & WV-1 \\
\hline Germination $(\%)^{\mathrm{x}}$ & & & & & \\
$\quad$ Control & $38.9 \mathrm{c}^{\mathrm{z}}$ & $21.9 \mathrm{~b}$ & $17.5 \mathrm{~b}$ & 58.0 & 11.3 \\
Calcium chloride & $64.8 \mathrm{~b}$ & $51.5 \mathrm{a}$ & $6.5 \mathrm{~b}$ & 53.1 & 22.3 \\
Calcium hydroxide & $66.4 \mathrm{~b}$ & $51.6 \mathrm{a}$ & $43.4 \mathrm{a}$ & 51.1 & 17.3 \\
Calcium propionate & $65.5 \mathrm{~b}$ & $44.2 \mathrm{a}$ & $9.3 \mathrm{~b}$ & 52.3 & 25.0 \\
Calcium silicate & $69.8 \mathrm{a}$ & $47.6 \mathrm{a}$ & $36.1 \mathrm{a}$ & 47.7 & 16.3 \\
Germ tube length $(\mu \mathrm{m})^{\mathrm{y}}$ & & & & & \\
Control & 24.2 & $24.6 \mathrm{bc}$ & 5.3 & 26.8 & 33.4 \\
Calcium chloride & 29.2 & $29.1 \mathrm{a}$ & 23.6 & 27.0 & 42.2 \\
Calcium hydroxide & 29.0 & $28.2 \mathrm{ab}$ & 6.9 & 28.7 & 36.9 \\
Calcium propionate & 28.0 & $21.8 \mathrm{c}$ & 13.4 & 25.6 & 37.2 \\
Calcium silicate & 28.0 & $25.0 \mathrm{bc}$ & 6.8 & 25.8 & 35.8 \\
\hline
\end{tabular}

${ }^{x}$ Values are the means of 300 measurements (50 conidia measured from three replicates with data from two experiments combined).

${ }^{y}$ Values are the means of 60 measurements $(10$ germ tubes measured from three replicates with data from two experiments combined).

${ }^{\mathrm{z}}$ Letters denote significant differences among means in columns according to the Waller-Duncan test $(P=0.05)$.

Table 4. Simple linear regression parameters for mycelial growth (g dry weight) of Botryosphaeria dothidea isolates in potato dextrose broth amended with calcium salts ${ }^{\mathrm{y}}$

\begin{tabular}{lccrrc}
\hline Salt & Isolate & Intercept & Slope $\left(\mathbf{B}_{\mathbf{1}}\right)$ & $\boldsymbol{F}$ value & Significance $^{\mathbf{z}}$ \\
\hline Calcium chloride & MD-1 & 0.21 & 0.000050 & 5.03 & $0.09^{*}$ \\
& PA-1 & 0.18 & -0.000014 & 0.16 & 0.71 \\
& PA-2 & 0.076 & 0.000078 & 61.22 & $0.001^{* * *}$ \\
& PA-3 & 0.19 & 0.000025 & 0.67 & 0.46 \\
& PA-4 & 0.16 & 0.000051 & 7.47 & $0.05^{* *}$ \\
& WV-1 & 0.12 & 0.000057 & 2.70 & 0.18 \\
Calcium hydroxide & MD-1 & 0.14 & 0.000010 & 0.44 & 0.54 \\
& PA-1 & 0.19 & 0.000039 & 3.89 & 0.12 \\
& PA-2 & 0.26 & 0.000025 & 0.47 & 0.53 \\
& PA-3 & 0.069 & 0.000066 & 44.70 & $0.003^{* * *}$ \\
& PA-4 & 0.14 & 0.000120 & 4.70 & $0.10^{*}$ \\
Calcium propionate & WV-1 & 0.23 & 0.000061 & 11.26 & $0.03^{* *}$ \\
& MD-1 & 0.16 & -0.000020 & 0.95 & 0.38 \\
& PA-1 & 0.19 & -0.000081 & 4.71 & $0.10^{*}$ \\
& PA-2 & 0.12 & -0.000055 & 7.21 & $0.06^{*}$ \\
& PA-3 & 0.14 & -0.000033 & 10.0 & $0.03^{* *}$ \\
& PA-4 & 0.16 & -0.000047 & 0.79 & 0.42 \\
& WV-1 & 0.032 & -0.000011 & 6.50 & $0.06^{*}$ \\
& MD-1 & 0.22 & 0.000038 & 1.43 & 0.29 \\
& PA-1 & 0.13 & 0.000048 & 1.44 & 0.29 \\
& PA-2 & 0.22 & -0.000072 & 16.99 & $0.01^{* * *}$ \\
& PA-3 & 0.26 & 0.000064 & 2.83 & 0.18 \\
& PA-4 & 0.14 & -0.000034 & 2.97 & 0.16 \\
& WV-1 & 0.11 & -0.000025 & 1.35 & 0.31 \\
\hline
\end{tabular}

${ }^{\mathrm{y}}$ Linear regression where $\mathrm{Y}=$ mycelial weight ( $\mathrm{g}$ dry weight) and $\mathrm{X}=$ concentration of calcium amendment of $0,300,600,900,1,200$, and $2,400 \mathrm{mg} / \mathrm{liter}$.

${ }^{\mathrm{z}}$ Asterisks denote significance at $P \leq 0.10(*), P \leq 0.05$ (**), and $P \leq 0.01$ (***). selected for investigation. The basis for the differing responses among isolates was thought to be related to differences in polygalacturonase isoenzyme composition, the components of which may vary in sensitivity to inhibition by calcium ions. In the present study, isolate PA-1 grew similarly or was stimulated in the presence of calcium salts compared to the control, whereas isolate PA-4 was similar or inhibited in the presence of calcium salts compared to the control (except for experiment 2). Additional studies are needed to determine the basis for the variability in sensitivity to calcium among different isolates.

In earlier studies, calcium salts directly suppressed the bitter rot pathogens, $C$. gloeosporioides and $C$. acutatum (3). Suppressive effects included reduced germ tube growth, reduced mycelial growth in vitro, and reduced severity of infection of host tissues pretreated with calcium. Also, bitter rot incidence on Golden Delicious was reduced at the lowest inoculum concentration tested. Although calcium salts did not reduce germination of $B$. dothidea spores in this study, reduced germination of Penicillium digitatum spores exposed to calcium chloride has been observed (17), as well as reduced germination and germ tube growth of $P$. expansum and Botrytis cinerea (25). Calcium salts also have been shown to reduce mycelial growth in vitro and reduce incidence and severity of infection of peach fruits and shoots by Monilinia fructicola and Leucostoma persoonii, respectively $(4,5,8)$.

The mechanisms by which fungi are sensitive to or tolerant of calcium salts are not known. One hypothesis is that high external concentrations of $\mathrm{Ca}^{2+}$ may lead to increased concentration of $\mathrm{Ca}^{2+}$ in the cytosol (17), which may be toxic to the fungus. Since maintenance of low basal concentrations of internal $\mathrm{Ca}^{2+}$ is essential for normal cell functions, organisms with the inability to regulate intracellular $\mathrm{Ca}^{2+}$ may exhibit compromised growth and development. Those that can regulate intracellular $\mathrm{Ca}^{2+}$ may grow normally. Calcium ions may reduce the incidence of fungal infection by directly inhibiting fungal growth, decreasing the production by fungi of cell-wall-degrading enzymes, and/or by being incorporated into the cell wall, thus making it less accessible to cellwall-degrading enzymes produced by the pathogens $(4,5,14,17)$.

In the mid-Atlantic region, apples may be infected by a wide variety of diseasecausing fungi. Most of the fungicides used on apples possess a broad spectrum of activity so that multiple diseases are usually controlled with each fungicide application. The major fungal pathogens during the early part of the growing season are apple scab (Venturia inaequalis), powdery mildew (Podosphaera leuco- 
tricha), and cedar-apple rust (Gymnosporangium juniperi-virginianae). Later, after the fruit are set, apple scab can continue to be problem if scab lesions are present on foliage, and powdery mildew can continue to develop, especially on susceptible cultivars. As fruit develop, they are susceptible to the "summer diseases," which include white rot, bitter rot ( $\mathrm{Col}$ letotrichum spp.), black rot (B. obtusa), sooty blotch (a complex of fungal organisms), and flyspeck (Zygophiala jamaicensis). The role of calcium supplementation in the integrated management of apple diseases is not well defined because few pathogens have been examined in sufficient detail. Most of our current knowledge pertains to Colletotrichum spp. and the postharvest pathogens discussed above. In the preharvest environment, calcium chloride and other calcium salts have shown suppressive activity against $V$. inaequalis, $P$. leucotricha, and G. juniperivirginianae in research trials (2); however, the early part of the growing season, when these fungi pose the greatest threat, is not when calcium applications would be made for managing calcium-related deficiency disorders, nor does calcium alone provide sufficient suppression of these diseases to prevent economic losses. In the middle to late part of the growing season, when calcium chloride would normally be applied for its fruit quality effects, no reduction in incidence of sooty blotch or flyspeck has been observed, although their severity may be reduced $(2,6)$. Based on earlier work, some reduction in the incidence of bitter rot could occur with calcium chloride (the only commonly applied calcium salt used in this study) applications if the particular cultivar is not highly susceptible (3). For white rot, application of calcium chloride would have no effect or might increase infection incidence. There are no data on the effects of calcium salts on the incidence of black rot. Although further research is required, given the potential for stimulatory effects by some calcium salts on disease development, their use alone may have only a limited role in disease management of apples destined for processing. Continued use of calcium in combination with fungicides is still justified based on its beneficial effects on fruit quality.

\section{ACKNOWLEDGMENTS}

The technical assistance of Robert Young and Shannon Moreland is gratefully acknowledged.

\section{LITERATURE CITED}

1. Bateman, D. F., and Lumsden, R. D. 1965. Relation of calcium content and nature of the pectic substances in bean hypocotyls of different ages to susceptibility of an isolate of Rhizoctonia solani. Phytopathology 55:734738.

2. Biggs, A. R. 1999. Evaluation of calcium chloride for apple disease control, 1994-1997. Biol. Cultural Tests Control Plant Dis. 15:47-48.

3. Biggs, A. R. 1999. Effects of calcium salts on apple bitter rot caused by two Colletotrichum spp. Plant Dis. 83:1001-1005.

4. Biggs, A. R., El-Kholi, M. M., and ElNeshawy, S. M. 1994. Effect of calcium salts on growth, pectic enzyme activity, and colonization of peach twigs by Leucostoma persoonii. Plant Dis. 78:886-890.

5. Biggs, A. R., El-Kholi, M. M., El-Neshawy, S., and Nickerson, R. 1997. Effects of calcium salts on growth, polygalacturonase activity, and infection of peach fruit by Monilinia fructicola. Plant Dis. 81:399-403.

6. Biggs, A. R., Hogmire, H. W., and Collins, A. R. 2000. Assessment of an alternative IPM program for the production of apples for processing. Plant Dis. 84:1140-1146.

7. Biggs, A. R., Ingle, M., and Solihati, W. D. 1993. Control of Alternaria infection of fruit of apple cultivar Nittany with calcium chloride and fungicides. Plant Dis. 77:976-980.

8. Biggs, A. R., and Peterson, C. A. 1990. Effect of chemical applications to peach bark wounds on accumulation of lignin and suberin and susceptibility to Leucostoma persoonii. Phytopathology 80:861-865.

9. Brown-Rytlewski, D. E., and McManus, P. S. 2000. Virulence of Botryosphaeria dothidea and Botryosphaeria obtusa on apple and management of stem cankers with fungicides. Plant Dis. 84:1031-1037.

10. Chardonnet, C. O., Sams, C. E., Trigiano, R. N., and Conway, W. S. 2000. Variability of three isolates of Botrytis cinerea affects the inhibitory effects of calcium on this fungus. Phytopathology 90:769-774.

11. Conway, W. S. 1982. Effect of postharvest calcium content on decay of Delicious apples. Plant Dis. 66:402-403.
12. Conway, W. S., Greene, G. M., II, and Hickey, K. D. 1987. Effects of preharvest and postharvest calcium treatments on peaches on decay caused by Monilinia fructicola. Plant Dis. 71:1084-1086.

13. Conway, W. S., Gross, K. C., and Sams, C. E 1987. Relationship of bound calcium and inoculum concentration to the effect of postharvest calcium treatment on decay of apples caused by Penicillium expansum. Plant Dis. 71:78-80.

14. Conway, W. S., and Sams, C. E. 1984. Possible mechanisms by which postharvest calcium treatment reduces decay in apples. Phytopathology 74:208-210.

15. Conway, W. S., Sams, C. E., Brown, G. A., Beavers, W. B., Tobias, R. B., and Kennedy, L. S. 1994. Pilot test for the commercial use of postharvest pressure infiltration of calcium into apples to maintain fruit quality in storage. HortTechnology 4:239-243.

16. Conway, W. S., Sams, C. E., McGuire, R. G. and Kelman, A. 1992. Calcium treatment of apples and potatoes to reduce postharvest decay. Plant Dis. 76:329-334.

17. Droby, S., Wisniewski, M. E., Cohen, L., Weiss, B., Touitou, D., Eilam, Y., and Chalutz, E. 1997. Influence of $\mathrm{CaCl}_{2}$ on Penicillium digitatum, grapefruit peel tissue, and biocontrol activity of Pichia guilliermondii. Phytopathology 87:310-315.

18. Fenner, E. A. 1925. A soft rot of apples caused by Botryosphaeria ribis. Phytopathology 15:230-234.

19. Parker, K. C., and Sutton, T. B. 1993 Susceptibility of apple fruit to Botryosphaeria dothidea and isolate variation. Plant Dis. 77:385-389.

20. Pfeifer, D. G. 2003. Virginia, West Virginia, Maryland Commercial Tree Fruit Spray Bulletin. Va. Coop. Ext. Serv. Publ. 456-419.

21. Putterill, V. A. 1919. A new apple tree canker. So. Afr. J. Sci. 16:258-272.

22. Shay, J. R., and Sitterly, W. R. 1954. Botryosphaeria canker of apple. (Abstr.) Phytopathology 44:505.

23. Sugar, D., Roberts, R. G., Hilton, R. J. Righetti, T. L., and Sanchez, E. E. 1994. Integration of cultural methods with yeast treatment for control of postharvest fruit decay in pear. Plant Dis. 78:791-795.

24. Sutton, T. B. 1991. White Rot. Pages 16-18 in: Compendium of Apple and Pear Diseases. A L. Jones and H. Aldwinckle, eds. American Phytopathological Society, St. Paul, MN.

25. Wisniewski, M. E., Droby, S., Chalutz, E., and Elam, Y. 1995. Effects of $\mathrm{Ca}^{2+}$ and $\mathrm{Mg}^{2+}$ on Botrytis cinerea and Penicillium expansum in vitro and on the biocontrol activity of Candida oleophila. Plant Pathol. 44:1016-1024. 